\title{
VOR BERICHT.
}

Seit mehrern Jahren fand ich in dem Studium der ältern deutfchen Literatur angenehme Befchäftigung und Erholung für meine Nebenftunden; und von Zeit zu Zeit theilte ich den Erfolg meiner Unterfuchungen und gelegentlichen Entdeckungen in verfchiedenen Zeitfchriften dem deutfchen Publikum mit. Der Glieder diefes letztern find freilich nicht gar viele, die an Gegenftänden diefer Art lebhaftes Intereffe nehmen; indefs fcheint fich ihre Anzahl doch während der letzteu Jahrzehnde vermehrt, und die Liebe zu den Alterthïmern vaterländifcher Literatur keiven unbeträchtlichen Zuwachs erhalten zu haben. Diefe mir erfreuliche Bemerkung, upd der bef 
mir immer reger gewordne Wunfch, zur Verbreitung diefes Studiums mitwirken zu können, vereint mit dem Beifall, welchen Männer von Anfehen meinen Bemühungen fchenkten, wurden mir Ermunterungen, jene zerftreuten Auffätze wieder zur Hand zu nehmen. Verbeffert und durch manche Zufätze erweitert geb' ich fie alfo bier in einer Sammlung, die aufserdem noch einige neue und $\int_{p}$ äter entworfene Beiträge zur altdeutfchen Dichterliteratur enthält. Sollte diefe Sammlung Beifall fuden, fo bin ich niclit ahgeneigt, fie fortzufetzen, und künftig mehr dergleichen Forfchungen mitzutheilen, deren Stof in meinen Händen, und zum Theil fchon wirklich verarbeitet ift.

Bei denen Stiicken diefer Sammlung, welche fchon eliedem, obgleich minder vollftändig, im Druck erfchienen find, ift in folgender Iuhaltsfanzeige ihre erfte Bekanntmachung nachgewiefen; die iibrigen werden hier zum erfteunal geliefert: 